\title{
Thermal and Textural Changes of Turkish Delight with Storage Relative Humidity
}

\author{
Sevim Kaya ${ }^{1}$ and Gökçe Özkaleli Tattan ${ }^{2}$ \\ 1. Food Engineering Department, Engineering Faculty, University of Gaziantep, Gaziantep 27310, Turkey \\ 2. Şölen Chocolate Food Industry and Trade Company, 4. Organized Zone, 83412 Street, No. 4, Şehitkamil, Turkey
}

\begin{abstract}
Lokum (Turkish delight) is a high sugar and starch containing food. Since the major deterioration factor affecting the storability of lokum is moisture gain or loss, the effect of the possible ambient conditions $\left(32 \%, 53 \%, 75 \% \mathrm{RH}\right.$ and $\left.15,25,35{ }^{\circ} \mathrm{C}\right)$ on weight change and firmness of lokum was determined to estimate its structural changes. The variations in thermal properties of lokum samples stored at different RH (32, 53, 65, 75, and 85\% RH) were also determined. Increasing RH decreased glass transition of lokum samples, and two glass transitions $\left(\mathrm{T}_{\mathrm{g}}\right)$ were observed at 75 and $85 \% \mathrm{RH}$. The presence of the second $\mathrm{T}_{\mathrm{g}}$ could be related with phase separation which was increased with increasing moisture content and RH. Lokum should be kept at around $50 \% \mathrm{RH}$ and $15^{\circ} \mathrm{C}$, higher storage RH's and temperatures will cause the product to become unacceptable by the consumer within 20 days.
\end{abstract}

Key words: Firmness, glass transition temperature, lokum, texture.

\section{Introduction}

Lokum, Turkish delight, is a confectionary product containing mainly sugar and starch as the gel former. The most important quality parameter of lokum is its physical structure such as softness and elasticity. There is no definite physical or textural attribute of lokum in literature; however it has been only described that lokum should not be too hard and too soft. Another important attribute of lokum is chewiness and lokum should not be sticky or hard which brings problems for chewing [1].

The important quality parameters of a food may be microbial, textural, physical, chemical or physicochemical. Generally, the presence of unwanted physicochemical qualities or microbial levels are distinguished the end of shelf life of food product. The ingredients used, the processes applied, the storage conditions exposed, and whether a packaging system used or not, are all affective on storage stability. The most important effective component on shelf-life in a food product is moisture because the shelf life

Correspondence author: Sevim Kaya, professor, research fields: food processing and dairy products. determination is specified according to physical and chemical attributes of foods and moisture affects these properties [2].

It was concluded that conducting a systematic experimental study for understanding deterioration reaction kinetics with samples having known water activities/moisture content/glass transition temperatures $\left(\mathrm{T}_{\mathrm{g}}\right)$ will be helpful for controlling food stability and packaging requirement $[3,4]$. The rules of glass-transition concept are: (1) the food is the most stable at and below its glass transition, and (2) the higher the $\mathrm{T}-\mathrm{T}_{\mathrm{g}}$ (i.e. above glass transition), the higher the deterioration or reaction rates.

There are some reports showing thermal characterization of starch containing food products [5-7]. One of them was reported by Jouppila and Roos [5] who presented that crystallization behavior of amorphous starch is similar to the crystallization behavior of synthetic polymers and the difference in ( $T-\mathrm{T}_{\mathrm{g}}$ ) for gelatinized starch affects melting behavior of the crystallites formed and the extent of crystallization. Getting closer crystallization temperature to $T_{g}$, smaller and less perfect crystals 
will be formed than stability of starch containing product will be changed. The event can be expressed as decreasing in molecular mobility with decreasing temperature.

Since the composition and production steps of the confectionary products are so different and it is possible to state that there is not any similar product whose stability has been studied before. A unique study reported about stability of lokum by Batu [8] that lokum should be stored at room temperature (20 ${ }^{\circ} \mathrm{C}$ ). Effect of storage RH on stability of lokum was not studied before. The study was aimed to evaluate the stability of lokum related with structural changes with changing water activity, and planned with two steps: first step was applied to evaluate variations of thermal properties, mainly $\mathrm{T}_{\mathrm{g}}$, with water activity; At second step, lokum samples were stored at different storage conditions (\% RH and temperature) to analyze possible changes in weight and firmness with changing water activity and storage temperature.

\section{Materials and Methods}

\subsection{Materials}

Lokum samples were prepared in a local factory using the commercial recipe (47\% sugar, $47 \%$ water, $6 \%$ corn starch). After production of lokum, samples were brought to laboratory and placed into nine different cabinets having different $\mathrm{RH}$ and temperatures. $\mathrm{RH}$ values were adjusted to $32 \% \pm 1 \%, 53 \% \pm 1 \%$, and $75 \%$ $\pm 1 \%$ with saturated salt solutions $\mathrm{MgCl}_{2}, \mathrm{MgNO}_{3}$ and $\mathrm{NaCl}$, respectively. The samples were kept in cabinets at 15,25 and $35{ }^{\circ} \mathrm{C}$ for about 30 days and analyses were applied periodically. All chemical used were of reagent grade.

\subsection{Determination of Weight and Firmness Change during Storage of Lokum}

Samples were stored in cabinets (Vötsch Industrietechnik, VC 0034) adjusted to 32, 53, and 75\% RH using saturated salt solutions placed into cabinets without contacting the samples at each studied temperature values of 15,25 , and $35{ }^{\circ} \mathrm{C}$. Samples were separated into two different sets for each condition; one set for determination of weight change and one for analyzing the change in firmness to estimate the possible structural variations in lokum related with storage RHs. For each condition, the weight change of the same sample was followed by weighing it periodically and replacing it back to the respective cabinet. Six lokum samples were examined for each condition and average of them were used to show weight change during 30 days storage.

Firmness of the stored samples was checked from the magnitude of force applied to the sample by using TA.XT plus Texture Analyzer (Stable Microsystems Ltd., Godalming, Surrey, UK) with the Texture Expert program. The samples stored at each condition were compressed with a stainless steel cylinder probe (2 mm diameter) at speed $1 \mathrm{mms}^{-1}$ to reach $25 \%$ strain. Five lokum samples were used for each measurement time and the reported results were the average values of them. Every time after firmness analysis, measured samples were discarded from the systems.

\subsection{Thermal Properties Determination}

Samples were conditioned using Dynamic Vapor Sorption Instrument (DVS-1/1000; Surface Measurement Systems Ltd, Alperton, UK) at $25{ }^{\circ} \mathrm{C}$ until to constant weight was reached at a certain $\mathrm{RH}$ value (32, 53, 65, 75, and 85\% RH). After reaching constant weight which means water activity of samples reached an equilibrium with instrumental $\mathrm{RH}$, the glass transition temperature was measured using DSC (DSC 4000 Perkin Elmer, Holland). Equilibrium was considered to have been reached when the change in mass was less than $0.001 \mathrm{mg} \mathrm{min}{ }^{-1}$. Each sample about $10 \mathrm{mg}$ was hermetically sealed in an aluminum pan, immediately after getting from DVS. Pans were heated to $200{ }^{\circ} \mathrm{C}$ at $10{ }^{\circ} \mathrm{C} \mathrm{min}^{-1}$ for scanning with the empty pan as a reference. Glass transition temperature $\left(T_{g}\right)$, onset $\left(T_{0}\right)$, and endpoint temperature $\left(T_{e}\right)$ values were obtained from DSC. 
The glass transition temperature and moisture content relationship was modeled using Gordon-Taylor Equation [9]:

$$
\mathrm{T}_{\mathrm{g}}=\frac{\mathrm{X}_{\mathrm{s}} \mathrm{T}_{\mathrm{gs}}+\mathrm{k}_{\mathrm{GT}} \mathrm{X}_{\mathrm{w}} \mathrm{T}_{\mathrm{gw}}}{\mathrm{x}_{\mathrm{s}}+\mathrm{k}_{\mathrm{GT}} \mathrm{X}_{\mathrm{w}}}
$$

where $\mathrm{X}_{\mathrm{S}}$ and $\mathrm{X}_{\mathrm{W}}$ were the mass fraction of solid and water, respectively. $\mathrm{T}_{\mathrm{g}}, \mathrm{T}_{\mathrm{gs}}, \mathrm{T}_{\mathrm{gw}}$ were the glass transition temperature of mixture, solids and water, respectively. $\mathrm{T}_{\mathrm{gw}}$ is $-135{ }^{\circ} \mathrm{C}$ and $\mathrm{k}_{\mathrm{GT}}$ was the Gordon Taylor parameter.

\subsection{StatisticalAnalysis}

Linear and nonlinear regression analyses were performed using Sigma Plot for Windows 12.3 (2011 Systat Software, Inc.). Analysis of variance (ANOVA) was carried out to determine the effect of time and $\mathrm{RH}$ (and related equilibrium water activity of sample) factors on weight change and firmness of lokum using SPSS software (v.21.0.0). Univariate linear model was used and Duncan test was applied as post-Hoc test.

\section{Results and Discussion}

\subsection{Effect of Storage Conditions on Weight Change and Firmness of Lokum}

The changes in weight of lokum stored at three different RH's and temperatures are presented in Fig. 1. Samples gained weight at $75 \% \mathrm{RH}$ and lost weight at $32 \% \mathrm{RH}$ at all temperatures studied while at medium RH (53\%) the trend was not so obvious. The samples stored at $53 \% \mathrm{RH}$ at $15{ }^{\circ} \mathrm{C}$ gained or at least kept their original weight and it was observed that increasing temperature from $15{ }^{\circ} \mathrm{C}$ to $25^{\circ} \mathrm{C}$ caused losing moisture and decreasing of sample weight but this temperature change was found to be not significant $(p>0.05)$. Further increase in the temperature at 53\% $\mathrm{RH}$ increased moisture loss, and this was statistically significant $(p<0.05)$. Hence a conclusion could be derived that effect of temperature on weight change of lokum was $\mathrm{RH}$ related. It was evaluated that effect of RH and storage time studied was significant for all samples $(p<0.05)$. This might be explained with improving water sorption of starch and sugar with increasing temperature. Increasing temperature at $75 \% \mathrm{RH}$ caused very remarkable changes in weight however this effect was seen at samples stored at other relative humidities but in a lower extent. Lokum samples gain a high amount of moisture at the highest $\mathrm{RH}$ and temperature, then they lost their shape and dissolution was observed. It was clearly seen that the surface of these lokum samples

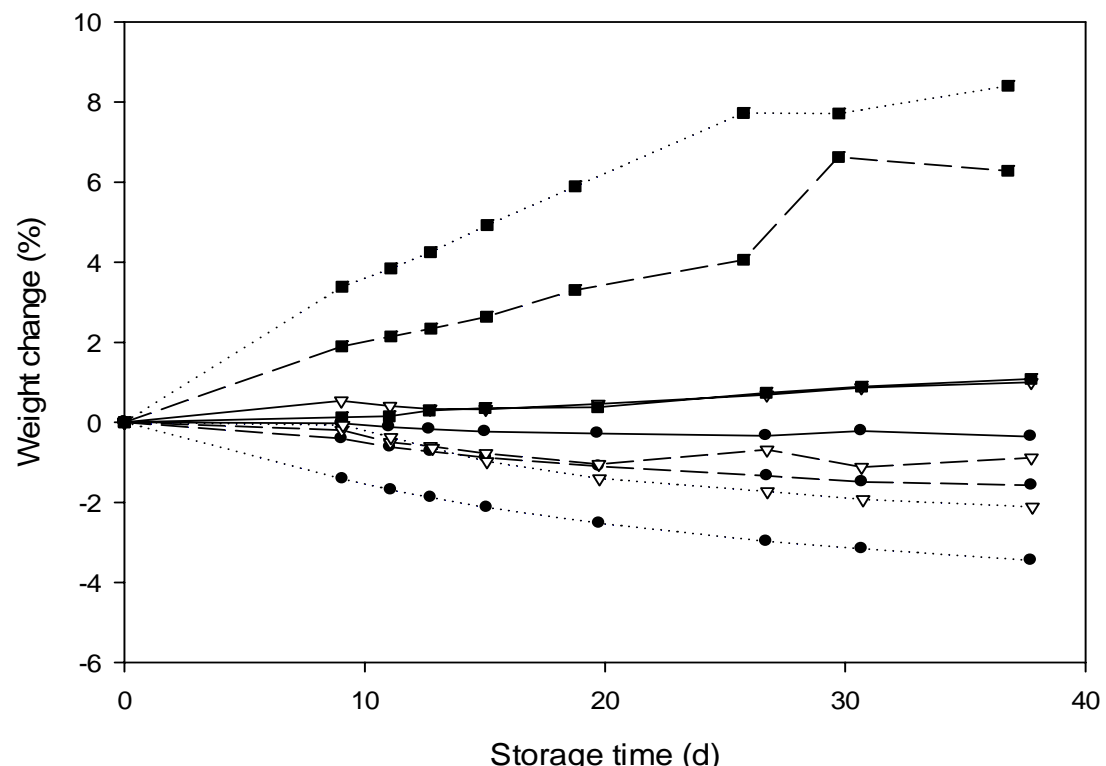

Fig. 1 Weight change of lokum during storage at $32 \% \mathrm{RH}(\bullet), 53 \%$ RH $(\nabla)$ and $75 \% \mathrm{RH}(-)$ and $15{ }^{\circ} \mathrm{C}(-), 25{ }^{\circ} \mathrm{C}(----)$, and $35^{\circ} \mathrm{C}$ (......). 


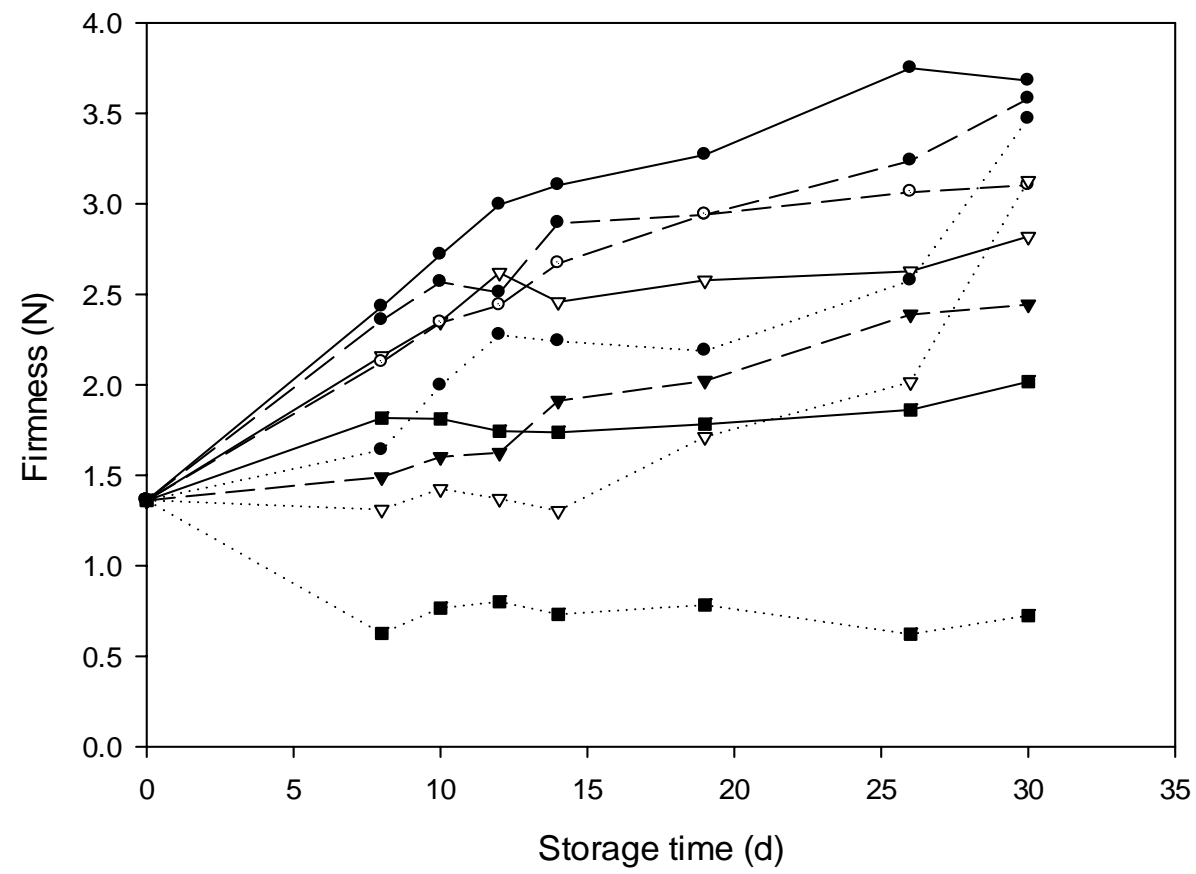

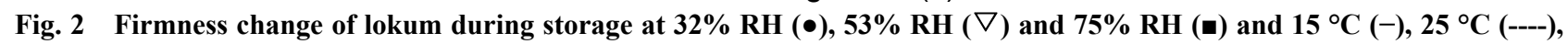
and $35^{\circ} \mathrm{C}(\ldots . .$.$) .$

became stickier than the samples stored at lower RH and temperature. At lower RH values lokum samples lost weight again in a high rate with increasing temperature.

Penetration forces of lokum samples stored at different storage conditions; 32, 53, and 75\% RH and 15,25 , and $35{ }^{\circ} \mathrm{C}$ temperatures were measured and plotted with respect to storage time (Fig. 2). The highest penetration value was obtained for lokum at $32 \% \mathrm{RH}$ and $15{ }^{\circ} \mathrm{C}$. Increasing RH caused dramatic decline in penetration at constant temperature and increasing the temperature decreased the penetration value at the same RH. The lowest penetration force was obtained for lokum samples stored at $75 \% \mathrm{RH}$ at $35{ }^{\circ} \mathrm{C}$ due to absorbing higher amount of water and then becoming softer than the other samples. These samples were found to be very sticky and they were no more acceptable to consume.

The ANOVA results showed that there were significant $(p<0.05)$ effects of time, temperature and RH on penetration force, except changing temperature from 15 to 25 were found to be not statistically significant $(p>0.05)$.

\subsection{Thermal Analysis}

Lokum samples were conditioned to get specific $\mathrm{a}_{\mathrm{w}}$ with adjusting RH of DVS instrument. After reaching these RH related $a_{w}$ values, samples were placed into DSC to measure their thermal properties which were listed in Table 1. It was observed that glass transition temperature decreased when $\mathrm{RH}$ of the storage conditions of lokum was increased, possibly due to the plasticizer effect of water as it was expressed by Vasquez et al. [10]. Lokum samples gained moisture with increasing $\mathrm{a}_{\mathrm{w}}$. Similar decreasing trend was also determined for the other thermal properties of lokum with increasing $\mathrm{a}_{\mathrm{w}}$. The same results were reported in several sugar-based food products $[9,11]$. $T_{g}$ values of lokum found in the study were comparable with the literature values that sucrose, fructose, glucose, lactose and maltose were $62-70,5,31,101$, and $87^{\circ} \mathrm{C}$, respectively, and that of starch as within a range of 55-75 ${ }^{\circ} \mathrm{C}$ [1]. The glass transition temperature depends on molecular weight, degree of cross-linking of polymer, and plasticizer (e.g., water) concentration [12]. It is clear that sugars with low molecular weight 
Table 1 The glass transition $\left(T_{g}\right)$, Onset $\left(T_{0}\right)$, and end point $\left(T_{e}\right)$ temperatures of lokum samples having different $a_{w}$ values.

\begin{tabular}{llll}
\hline $\mathrm{a}_{\mathrm{w}}$ & $\mathrm{T}_{\mathrm{g}}\left({ }^{\circ} \mathrm{C}\right)$ & $\mathrm{T}_{\mathrm{o}}\left({ }^{\circ} \mathrm{C}\right)$ & $\mathrm{T}_{\mathrm{e}}\left({ }^{\circ} \mathrm{C}\right)$ \\
\hline 0.32 & 91.410 & 80.660 & 104.490 \\
0.53 & 84.270 & 76.400 & 92.260 \\
0.65 & 80.800 & 69.110 & 87.950 \\
0.75 & 79.000 & 72.750 & 86.090 \\
0.85 & 78.800 & 68.180 & 90.110 \\
\hline
\end{tabular}

generally have lower $T_{\mathrm{g}}$, whereas those with high molecular weight generally have higher $T_{g}[13,14]$. Farahnaky et al. [15] reported that not only the molecular weight, but also mixing of different kinds of sugars and starch which is the case in lokum manufacturing, and heating processes applied possibly affect the $\mathrm{T}_{\mathrm{g}}$ of final products.

Gordon Taylor model (Eq. 1) was applied to define $\mathrm{T}_{\mathrm{g}}$ of lokum. The $\mathrm{T}_{\mathrm{gs}}$ and $\mathrm{k}_{\mathrm{GT}}$ parameters of Gordon Taylor were found as $353.16 \pm 0.6 \mathrm{~K}$ and $-5.27 \times 10^{-4}$, respectively and correlation coefficient of the model application $\left(\mathrm{R}^{2}\right)$ was found to be 0.980 and SEE was 0.784 . A value of SEE lower than $10 \%$ is indicative of good fit of experimental data with models for practical purposes [10]. It was possible to state that Gordon-Taylor model was found to be sufficient to describe the relation. The variations of $T_{g}$ values of lokum with respect to storage $\mathrm{RH}$ values applied were presented in Fig. 3 with predicted values using Gordon Taylor Equation.

It was important to state that two glass transitions were observed for the lokum samples stored at high RHs (75\% and $85 \%)$. The second glass transition temperatures were $101.29^{\circ} \mathrm{C}$ at $75 \%$ and $147.33^{\circ} \mathrm{C}$ at $85 \%$. Increasing storage $\mathrm{RH}$ and $\mathrm{a}_{\mathrm{w}}$ of lokum increased the second transition which reverse trend was expected according to Forssell et al. [16]. They analyzed thermal behavior of starch-glycerol-water mixture and found that the presence of one or two transitions was directly depending on both water and glycerol content. They suggested that presence of a single phase system has been occurred at low water and glycerol contents caused one transition, while phase separation occurred and the system was composed of starch-rich and starch-poor phases resulted in two transitions, and they reported that increasing $\mathrm{a}_{\mathrm{w}}$ decreased both upper and lower $\mathrm{T}_{\mathrm{g}}$ values. In the case of lokum increasing $\mathrm{RH} /$ water activity/water content after a certain point increased the second transition possibly due to the increasing

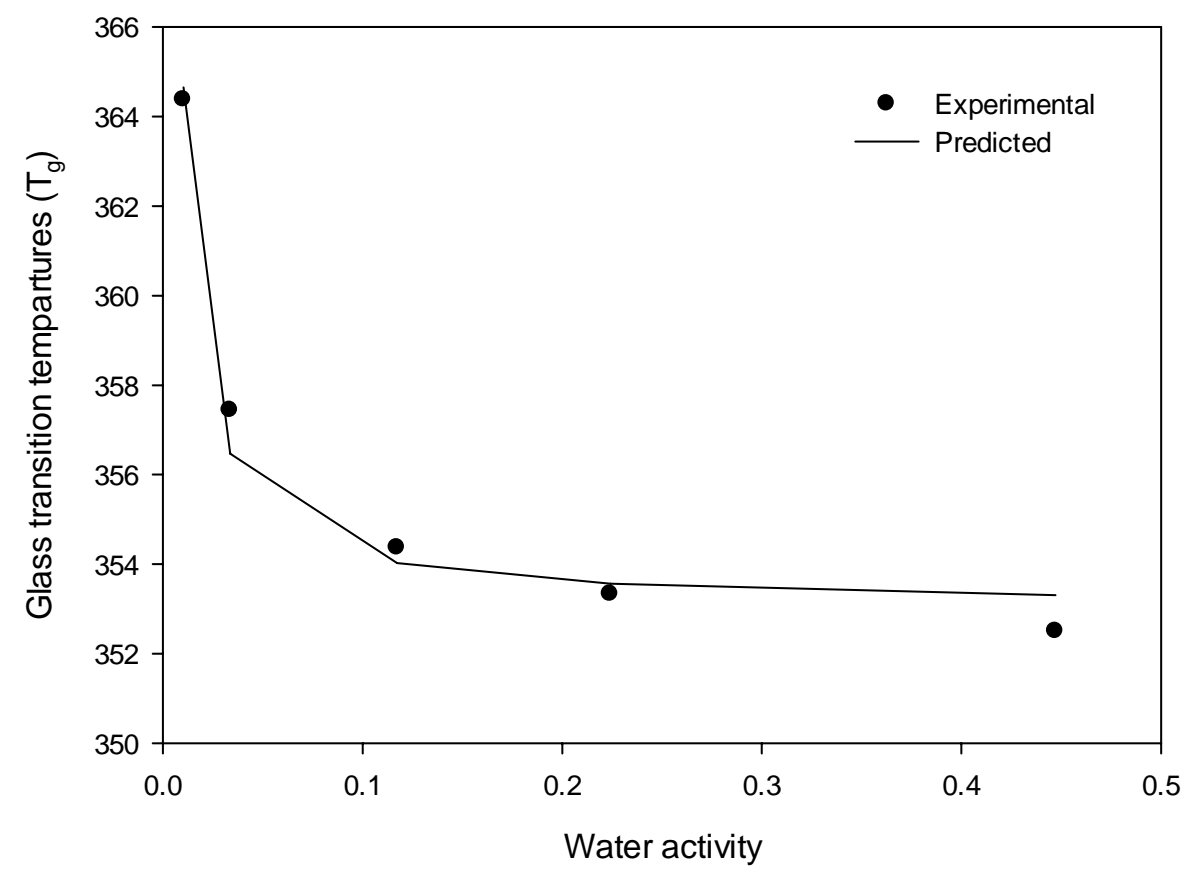

Fig. 3 Changes of glass transition ( $\left.T_{g}\right)$ as a function of $a_{w}$ for lokum. 
phase separation and recrystallization of amylopectin in the water solution. Increasing moisture content changed the physical structure; lokum stored at high RH condition became sticky and juicy. It could be possible to conclude that with increasing $\mathrm{RH}$ phase separation was enforced and this caused an increase in second $\mathrm{T}_{\mathrm{g}}$ value.

\section{Conclusions}

When storage RH was increased, thermal properties of lokum samples were decreased, and for the samples stored at $75 \% \mathrm{RH}$ and $85 \% \mathrm{RH}$, second $\mathrm{T}_{\mathrm{g}}$ values were observed. The presence of the second $\mathrm{T}_{\mathrm{g}}$ could be related with phase separation which was increased with increasing $\mathrm{a}_{\mathrm{w}}$. It was observed that effect of both storage RH and temperature on all properties of lokum studied were significant $(p<0.05)$. It was possible to state that thelokum should be kept at a storage condition (at around $50 \% \mathrm{RH}$ and $15{ }^{\circ} \mathrm{C}$ ), higher $\mathrm{RH}$ and storage temperatures will cause the product to become unacceptable by the consumer within 20 days.

\section{References}

[1] Batu, A., and Kırmacı, B. 2009. "Production of Turkish Delight (Lokum).” Food Research International 42: 1-7.

[2] Ergun, R., Lietha, R., and Hartel, R. W. 2010. "Moisture and Shelf Life in Sugar Confections.” Critical Reviews in Food Science and Nutrition 50 (2): 162-92.

[3] Sablani, S. S., Kasapis, S., and Rahman, M. S. 2007. "Evaluating Water Activity and Glass Transition Concepts for Food Stability.” Journal of Food Engineering 78: 266-71.

[4] Rahman, M. S. 2010. "Food Stability Determination by Macro-Micro Region Concept in the State Siagram and by Defining a Critical Temperature.” Journal of Food Engineering 99: 402-16.

[5] Jouppila, K., and Roos, Y. H. 1997. Carbohydrate
Polymers. 32. Great Britain: Elsevier Science Ltd.

[6] Carlstedt, J., Wojtasz, J., Fyhr, P., and Kocherbitov, V. 2014. "Hydration and the Phase Diagram of Acid Hydrolyzed Potato Starch.” Carbohydrate Polymers 112: 569-77.

[7] Kawai, K., Toh, M., and Hagura, Y. 2014. "Effect of Sugar Composition on the Water Sorption and Softening Properties of Cookie.” Food Chem. 145: 772-6.

[8] Batu, A. 2011. "Production of Turkish Delight (Lokum) with Its Additives and Quality.” In ICEF11 International Congress on Engineering and Food, May 22-26, Athens, Greece.

[9] Cervenka, L., Kubinova, J., Juszczak, L., and Witczak, M. 2011. "Moisture Sorption Isotherms and Glass Transition Temperature of Elecampe (Inulahelenium L.) and Burdock (Arctiumlappa L.) Roots at $25{ }^{\circ} \mathrm{C} . ”$ Food Science and Technology International 18: 81-91.

[10] Vasquez, C., Diaz-Calderon, P., Enrione, J., and Matiacevich, S. 2013. "State Diagram, Sorption Isotherm and Color of Blueberries as a Function of Water Content.” Thermochimica Acta 570: 8-15.

[11] Nadia Djendoubi, M., Catherine, B., Nourhène, B., Nabil, K., and Francis, C. 2012. "Influence of Sugar Composition on Water Sorption Isotherms and on Glass Transition in Apricots.” Journal of Food Engineering 111: 403-11.

[12] Graaf de, E. M., Madeka, H., Cocero, A. M., and Kokini, J. L. 1993. "Determination of the Effect of Moisture on Gliadin Glass Transition Using Mechanical Spectrometry and Differential Scanning Calorimetry.” Biotechnol Prog. 9: 210-3.

[13] White, G. W., and Cakebread, S. H. 1966. "The Glassy State in Certain Sugar-Containing Food Products." $J$. Food Techno. 1: 73-82.

[14] Roos, Y. H. 2002. "Importance of Glass Transition and Water Activity to Spray Drying and Stability of Dairy Powders.” Journal of Food Science 82: 475-84.

[15] Farahnaky, A., Badii, F., Farhat, I. A., Mitchell, J. R., and Hill, S. E. 2005. "Enthalpy Relaxation of Bovine Serum Albumin and Implications for Its Storage in the Glassy State.” Biopolymers 78: 69-77.

[16] Forssell, P. M., Mikkila, J. M., Moates, G. K., and Parker, R. 1997. Carbohydrate Polymers. 34. Great Britain: Elsevier Science Ltd. 